The classification of malignant melanoma and its histologic reporting Cancer;32:1446-57.

6. Richard A Scolyer RA, Long GV and Thompson JF (1967). Moles and malignant melanoma: terminology and classification. Med J Aust; 1:123-5.
7. Breslow: A (1975). Tumor thickness, level of invasion and node dissection in stage I cutaneous melanoma. Ann Surg;182: 572-5.

8. Fleming: I.D, Greene FL, Page $D L$, et al (2010). AJCC Cancer Staging Manual, 7th edition. New York: Springer-Verlag.

\title{
KHẢO SÁT MỨC Độ THÍCH ỨNG ĐỐI VỚI HOẠT ĐộNG HỌC TÂPP CỦA SINH VIÊN NĂM THỨ NHẤT KHOA XÉT NGHIỆM TRƯỜ'NG ĐẠI HỌC KỸ THUÂTT Y TẾ HẢI DƯƠ'NG.
}

\section{TÓM TẮT}

Muc tiêu: Khảo sát mức đô thích ứng đối với hoat động học tâp của sinh viên năm thứ nhất khoa Xét nghiệm trường Đại học Kỹ thuật $Y$ tế Hải Dương và một số yếu tố ảnh hưởng. Phương pháp: Nghiên cứu ngang có phân tích. Kết quả: Thích ứng đối với hoạt động học tập của sinh viên năm thức nhất khoa Xét nghiệm trường Đại học Kỹ thuật $Y$ tế Hải Dương đạt ở mức thích ứng trung bình $(93,4 \%)$. Trong nhóm thích ứng trung bình có $40,2 \%$ sinh viên có kết quả học tập trung bình, 34,4\% sinh viên có kết quả khá, $0,8 \%$ sinh viên có kêt quả giỏi. Sinh viên còn gặp nhiều khó khăn trong việc theo kịp tiến độ học đại học, tỉ lệ sinh viên hài lòng với kết quả học tập và tình hình học tập của bản thân còn thấp. Trong các nhóm yếu tố ảnh hưởng tới mức độ thích ứng đối với học tập thì yếu tố bản thân sinh viển được đánh giá là ảnh hưởng nhiều nhất.

\section{SUMMARY}

\section{THE SURVEY OF ADAPTATION TO LEARNING ACTIVITIES OF THE FIRST- YEAR STUDENTS IN THE LABORATORY DEPARTMENT OF HAI DUONG MEDICAL TECHNICAL UNIVERSITY}

Objective: Survey of adaptation to learning activities of the first-year students in the Laboratory Department of Hai Duong Medical Technical University and a number of influencing factors. Subjects and methods: Cross-sectional survey. Results: The average adaptation to learning activities of the firstyear students in the Laboratory Department of Hai Duong Medical Technical University was $93,4 \%$. In the average adaptation group, $40,2 \%$ of students have average results and $0,8 \%$ of sudents have excellent results. Students still face many difficulties in keeping up with the progress of studying at university, the rate

*Trường Đại học Kỹ thuật Y tế Hải Dương

Chịu trách nhiệm chính: Mạc Thị Thảo

Email: thaomac.hmtu@gmail.com

Ngày nhận bài: 3.3.2021

Ngày phản biên khoa học: 19.4.2021

Ngày duyệt bài: 28.4.2021

\section{Mạc Thị Thảo*, Nguyễn Thị Kiều Liên*, Nguyễn Thị Nga*, Phạm Thị Thùy Nhu**}

of students satisfied with their study outcome and their learning situation is still low. Among the groups of factors that affected the adaptive level of learning, the factors that students themselves are considered to be the most influential.

\section{I. ĐĂT VẤN ĐỀ}

Tại Việt Nam hiện nay, giáo dục đại học đang là vấn đề được cả xã hội quan tâm. Giảng đường đại học là bước ngoặt iớn đối với mỗi sinh viên, đặc biệt là sinh viên năm thứ nhất. Cuộc sống ở trường đại học cho sinh viên năm đầu tiên đây thú vị nhưng cũng đầy thử thách. Một mặt, sinh viên năm thứ nhất sẽ thấy tự do hơn nhưng mặt khác họ sẽ phải tổ chức lại hoạt động học tập, xây dựng lại những mối quan hể cá nhân trong một môi trường mới và điều đó có thể gây ra những căng thẳng. Thích ứng tâm lý kém với môi trường đại học có thể buộc sinh viên phải rời khỏi trường. [1]

Thích ứng với hoạt động học tập là một yêu câu bắt buộc đối với sinh viên, đặc biệt là sinh viên năm đầu tiên. Đó chính là quá trình sinh viên tích cực chủ động làm quen, hòa nhập vào các điều kiện học tập mới khác về chất so với hoạt động học tập trong trường trung học phổ thông nhằm hình thành và phát triển nhân cách nghề nghiệp tương lai, thực hiện hiệu quả mục tiêu đào tạo của nhà trường và đáp ứng yêu cầu của xã hội hiện đại. [2]

Phần lớn sinh viên năm thứ nhất khoa Xét nghiệm trường Đại học Kỹ thuật $Y$ tế Hải Dương đều mới tốt nghiệp bậc học phổ thông. Sự chuyển tiếp này đã̉ tạo ra rất nhiều khác biệt trong hoạt động học tập như khối lượng, nội dung tri thức, phương pháp giảng dạy. Trường Đại học kỹ thuật $Y$ tế Hải Dương là một trong những trường đầu tiên thuộc khối ngành sức khoẻ giảng dạy theo học chế tín chỉ. Đào tạo theo học chế tín chỉ là mô hình đào tạo mới đối 
với giáo dục đại học Việt Nam, đòi hỏi người học phải nâng cao tính tích cực, chủ động nắm bắt những phương pháp, công cụ cần thiết để tự chiếm lĩnh tri thức dưới sự tố chức, định hướng của người thầy. Điều này khác xa so với cách học ở trường phổ thông hay theo chương trình đào tạo niên chế. Những khác biệt này đòi hỏi sinh viên năm thứ nhất phải nhanh chóng thích ứng với môi trường học tập, là điều kiện cần thiết để nâng cao chất lượng đào tạo của nhà trường. Từ thực tế này, chúng tôi lựa chọn nghiên cứu "Khảo sát mức độ thích ứng đối với hoạt động học tập của sinh viên năm thứ nhất khoa Xét nghiệm trường Đại học Kỹ thuật $Y$ tế Hải Dương". Nghiên cứu nhằm mục tiêu: Mô tả mức độ thích ứng với hoạt động học tập của sinh viên năm thứ nhất khoa Xét nghiệm tại trường Đại học Kỹ thuật $Y$ tế Hải Dương và xác định một số yếu tố ảnh hưởng .

\section{II. ĐỐl TƯợNG VÀ PHƯƠNG PHÁP NGHIÊN CỨU}

*Đối tượng nghiên cứu: Sinh viên năm thứ nhất khoa Xét nghiệm trường Đại học Kỹ thuật $Y$ tế Hải Dương.

- Tiêu chuẩn lựa chọn: Đồng ý tham gia nghiên cứu

- Tiêu chuẩn loại trừ: Không đồng ý tham gia nghiên cứu

*Thời gian và địa điểm nghiên cứu:

- Thời gian: Tháng 10/2019 đến tháng 6/2020

- Địa điểm: Trường Đại học Kỹ thuật Y tế Hải Dương

* Phương pháp nghiên cứu:

- Thiết kế nghiên cứu: Phương pháp nghiên cứu ngang có phân tích.

- Mẫu nghiên cứu: toàn bộ sinh viên năm thứ nhất hệ chính quy Khoa xét nghiệm (trúng tuyển năm 2019) trường Đại học Kỹ thuật $Y$ tế Hải Dương.

Bộ công cụ nghiên cứu và kỹ thuật thu thập số liệu

Công cụ thu thập số liệu: Để đánh giá mức độ thích ứng của sinh viên chúng tôi sử dụng một bảng câu hỏi được thiết kế dựa trên Bảng câu hỏi về sự thích ứng của sinh viên với môi trường đại học (gọi tắt là $\mathrm{SACQ}$ ) được phát triển bởi Robert W. Baker và Bohdan Siryk. Tại Việt Nam thang đo SACQ đã được tác giả Võ Văn Việt, trường Đại học Nông lâm thành phố Hồ Chí Minh đánh giá thông qua hệ số tin cậy Cronbach'Alpha là 0,890 . Tuy nhiển, với giới hạn của nghiên cứu này, chúng tôi chỉ sử dụng những câu hỏi liên quan đến thích ứng với hoạt động học tập. [3]

Bảng hỏi sử dụng trong nghiên cứu bao gồm
3 phân, phần 1 là các thông tin về sự thích ứng với hoạt động học tập, phần 2 là các yếu tố ảnh hưởng, phần 3 là các thông tin nhân khẩu học. Điểm số của mức độ thích ứng với hoạt động học tập là tổng điểm của 24 biến quan sát. Điểm càng cao thể hiện sự thích ứng càng tốt.

\section{Tính điểm:}

\begin{tabular}{|c|c|c|c|}
\hline Thang đo & $\begin{array}{c}\text { Thích ứng } \\
\text { thấp }\end{array}$ & $\begin{array}{c}\text { Thích ứng } \\
\text { trung bình }\end{array}$ & $\begin{array}{c}\text { Thích } \\
\text { ưng cao }\end{array}$ \\
\hline $\begin{array}{c}\text { Thích ứng } \\
\text { về mặt } \\
\text { học tập }\end{array}$ & $\begin{array}{c}\text { Từ } 24 \text { đến } \\
95\end{array}$ & $\begin{array}{c}\text { Từ } 96 \text { đến } \\
167\end{array}$ & $\begin{array}{c}\text { Từ } 168 \text { trở } \\
\text { lên }\end{array}$ \\
\hline
\end{tabular}

*Phân tích và xử lý số liệu. Số liêu được làm sạch trong quá trình kiểm tra phiếu, nhập liệu và kiểm tra bằng các phần mềm thống kê.

Nhập và hân tích số liệu: Sử dụng phần mềm SPSS 20.0 để phân tích số liệu.

\section{KẾT QUẢ NGHIÊN CứU}

\section{1. Đặc điểm chung về đối tượng} nghiên cứu

Bảng 3.1. Đặc điểm chung về đôî̉ tượng nghiên cứu

\begin{tabular}{|c|c|c|c|}
\hline \multicolumn{2}{|c|}{ Tiêu chí } & $\begin{array}{c}\text { Số } \\
\text { lượng }\end{array}$ & $\begin{array}{c}\text { Tỷ lệ } \\
(\%)\end{array}$ \\
\hline \multirow{2}{*}{$\begin{array}{c}\text { Giới } \\
\text { tính }\end{array}$} & Nam & 27 & 22,1 \\
\cline { 2 - 4 } & Nữ & 95 & 77,9 \\
\hline \multirow{3}{*}{$\begin{array}{c}\text { Nơi ở } \\
\text { hiện tại }\end{array}$} & Ký túc xá & 44 & 36 \\
\cline { 2 - 4 } & Nhà trọ/người quen & 70 & 57,4 \\
\hline \multirow{3}{*}{$\begin{array}{c}\text { Kết quả } \\
\text { học tập } \\
\text { học kỳ I }\end{array}$} & Ớ cùng cha mẹ & 8 & 6,6 \\
\cline { 2 - 4 } & Dưới TB & 15 & 12,3 \\
\cline { 2 - 4 } & Trung bình & 53 & 43,4 \\
\cline { 2 - 4 } & TB - Khá & 43 & 35,2 \\
\cline { 2 - 4 } & Khá & 10 & 8,2 \\
\hline
\end{tabular}

Mấu điêuu tra nghiên cứu này là 122 sinh viên chính quy năm thứ nhất Khoa xét nghiệm của trường Đại học kỹ thuât y tế Hải Dương. $36 \%$ sinh viên đang ở ký túc xá của trường, 57,4\% đang ở nhà trọ/ ở nhà người quen, $6,6 \%$ ở cùng cha me.

3.2. Mức độ thích ứng đối với học tập của sinh viên năm thứ nhất khoa Xét nghiệm

Bảng 3.2: Mức độ thích ứng đôî với học tập của sinh viên năm thứ nhất khoa Xét nghiệm

\begin{tabular}{|c|c|c|}
\hline Mức độ thích ứng & Tân suất & Tỷ lệ \% \\
\hline Thích ứng thấp & 1 & 0,8 \\
\hline Thích ứng trung bình & 114 & 93,4 \\
\hline Thích ứng cao & 7 & 5,7 \\
\hline Tống & $\mathbf{1 2 2}$ & $\mathbf{1 0 0}$ \\
\hline
\end{tabular}

93,4\% sinh viên thích ứng ở mức trung bình đối với học tập; $5,7 \%$ sinh viên có mức độ thích ứng cao và $0,8 \%$ sinh viên thích ứng ở mức độ thấp. 
Bảng 3.3: Thống kê mô tả tần suât và tỷ lệ \% sự thích ứng đôî với học tập

\begin{tabular}{|c|c|c|c|c|c|c|c|c|c|c|}
\hline & & & & & & & & & & \\
\hline \multirow{3}{*}{\begin{tabular}{|c|} 
Tiêu chí \\
$\begin{array}{c}\text { Bạn theo kịp tiến độ học tập ở bậc } \\
\text { đại học }\end{array}$
\end{tabular}} & & 1 & 2 & 3 & 4 & 5 & 6 & 7 & 8 & 9 \\
\hline & $\mathrm{n}$ & 7 & 5 & 9 & 16 & 47 & 16 & 15 & 2 & 5 \\
\hline & $\%$ & 5,7 & 4,1 & 7,4 & 13,1 & 38,5 & 13,1 & 12,3 & 1,6 & 4,1 \\
\hline \multirow{2}{*}{$\begin{array}{c}\text { Bạn biết rõ lý do và kết quả mong } \\
\text { đợi khi bạn học đại học }\end{array}$} & $\mathrm{n}$ & 7 & 4 & 2 & 8 & 35 & 15 & 15 & 11 & 25 \\
\hline & $\%$ & 5,7 & 3,3 & 1,6 & 6,6 & 28,7 & 12,3 & 12,3 & 9,0 & 20,5 \\
\hline \multirow{2}{*}{$\begin{array}{c}\text { Bạn đang cảm thấy việc học đại } \\
\text { học thật khó khăn }\end{array}$} & $\mathrm{n}$ & 3 & 2 & 7 & 7 & 32 & 16 & 16 & 13 & 26 \\
\hline & $\%$ & 2,5 & 1,6 & 5,7 & 5,7 & 26,2 & 13,1 & 13,1 & 10,7 & 21,3 \\
\hline \multirow{2}{*}{$\begin{array}{c}\text { Bạn gặp khó khăn trong các kỳ thi } \\
\text { ở đại học }\end{array}$} & $n$ & 2 & 2 & 9 & 7 & 28 & 9 & 19 & 18 & 28 \\
\hline & $\%$ & 1,6 & 1,6 & 7,4 & 5,7 & 23,0 & 7,4 & 15,6 & 14,8 & 23,0 \\
\hline \multirow{2}{*}{$\begin{array}{l}\text { Bạn cảm thấy hài lòng về kết quả } \\
\text { học tập vừa qua của mình }\end{array}$} & $\mathrm{n}$ & 40 & 15 & 16 & 19 & 20 & 3 & 2 & 1 & 6 \\
\hline & $\%$ & 32,8 & 12,3 & 13,1 & 15,6 & 16,4 & 2,5 & 1,6 & 0,8 & 4,9 \\
\hline \multirow{2}{*}{$\begin{array}{c}\text { Có liên hệ, trao đổi với giảng viên } \\
\text { sau giờ học }\end{array}$} & $\mathrm{n}$ & 47 & 14 & 10 & 14 & 26 & 1 & 4 & 1 & 5 \\
\hline & $\%$ & 38,5 & 11,5 & 8,2 & 11,5 & 21,3 & 0,8 & 3,3 & 0,8 & 4,1 \\
\hline \multirow{2}{*}{$\begin{array}{l}\text { Bạn hài lòng với quyết định học ở } \\
\text { trường }\end{array}$} & $n$ & 6 & 6 & 9 & 14 & 39 & 9 & 12 & 13 & 17 \\
\hline & $\%$ & 4,9 & 4,9 & 7,4 & 11,5 & 32,0 & 4,9 & 9,8 & 10,7 & 13,9 \\
\hline \multirow{2}{*}{$\begin{array}{c}\text { Bạn chưa thật sự tích cực học tập } \\
\text { trong học kỳ vừa qua }\end{array}$} & $\mathrm{n}$ & 10 & 3 & 8 & 4 & 31 & 13 & 15 & 12 & 26 \\
\hline & $\%$ & 8,2 & 2,5 & 6,6 & 3,3 & 25,4 & 10,7 & 12,3 & 9,8 & 21,3 \\
\hline \multirow{2}{*}{$\begin{array}{l}\text { Bạn xác định được mục đích và } \\
\text { mục tiêu học tập rõ ràng }\end{array}$} & $\mathrm{n}$ & 10 & 3 & 9 & 11 & 42 & 9 & 17 & 9 & 12 \\
\hline & $\%$ & 8,2 & 2,5 & 7,4 & 9,0 & 34,4 & 7,4 & 13,9 & 7,4 & 9,8 \\
\hline \multirow{2}{*}{$\begin{array}{l}\text { Bạn không đủ thông minh để đạt } \\
\text { kết quả học tập như mong đợi }\end{array}$} & $n$ & 14 & 10 & 9 & 8 & 38 & 6 & 13 & 7 & 17 \\
\hline & $\%$ & 11,5 & 8,2 & 7,4 & 6,6 & 31,1 & 4,9 & 10,7 & 5,7 & 13,9 \\
\hline \multirow{2}{*}{$\begin{array}{c}\text { Bạn cảm thấy có tấm bằng đại học } \\
\text { là rất quan trọng }\end{array}$} & $\mathrm{n}$ & 5 & 3 & 3 & 1 & 19 & 4 & 16 & 8 & 63 \\
\hline & $\%$ & 4,1 & 2,5 & 2,5 & 0,8 & 15,6 & 3,3 & 13,1 & 6,6 & 51,6 \\
\hline \multirow{2}{*}{$\begin{array}{l}\text { Bạn không sử dụng thật sự hiệu } \\
\text { quả thời gian dành cho việc học }\end{array}$} & $\mathrm{n}$ & 3 & 2 & 7 & 1 & 28 & 10 & 15 & 15 & 41 \\
\hline & $\%$ & 2,5 & 1,6 & 5,7 & 0,8 & 23,0 & 8,2 & 12,3 & 12,6 & 33,6 \\
\hline \multirow{2}{*}{$\begin{array}{l}\text { Bạn thích làm các bài tiểu luâan cá } \\
\text { nhân, bài tập nhóm trong các học } \\
\text { kỳ vừa qua }\end{array}$} & $\mathrm{n}$ & 8 & 3 & 10 & 10 & 38 & 14 & 11 & 8 & 20 \\
\hline & $\%$ & 6,6 & 2,5 & 8,2 & 8,2 & 31,1 & 11,5 & 9,0 & 6,6 & 16,4 \\
\hline \multirow{2}{*}{$\begin{array}{l}\text { Bạn thực sự không có nhiều động } \\
\text { lực học tập ở bậc đại học }\end{array}$} & $\mathrm{n}$ & 12 & 9 & 12 & 5 & 45 & 12 & 10 & 4 & 13 \\
\hline & $\%$ & 9,8 & 7,4 & 9,8 & 4,1 & 36,9 & 9,8 & 8,2 & 3,3 & 10,7 \\
\hline \multirow{2}{*}{$\begin{array}{c}\text { Gần đây, bạn có cảm giác nghi } \\
\text { ngờ về giá trị của giáo dục đại học }\end{array}$} & $\mathrm{n}$ & 17 & 8 & 10 & 7 & 44 & 10 & 9 & 2 & 15 \\
\hline & $\%$ & 13,9 & 6,6 & 8,2 & 5,7 & 36,1 & 8,2 & 7,4 & 1,6 & 12,3 \\
\hline \multirow{2}{*}{$\begin{array}{c}\text { Bạn hài lòng với sự đa dạng của } \\
\text { các khóa học ở đại học }\end{array}$} & $\mathrm{n}$ & 6 & 2 & 6 & 13 & 49 & 5 & 14 & 12 & 15 \\
\hline & $\%$ & 4,9 & 1,6 & 4,9 & 10,7 & 40,2 & 4,1 & 11,5 & 9,8 & 12,3 \\
\hline \multirow{2}{*}{$\begin{array}{c}\text { Bạn gặp khó khăn khi tập trung } \\
\text { để học }\end{array}$} & $n$ & 7 & 3 & 5 & 9 & 25 & 8 & 18 & 16 & 31 \\
\hline & $\%$ & 5,7 & 2,5 & 4,1 & 7,4 & 20,5 & 6,6 & 14,8 & 13,1 & 25.3 \\
\hline \multirow{2}{*}{$\begin{array}{l}\text { Bạn đang bị quá tải với các bài tập, } \\
\text { tiểu luận, thuyết trình, học nhóm }\end{array}$} & $\mathrm{n}$ & 7 & 4 & 12 & 10 & 49 & 11 & 11 & 7 & 11 \\
\hline & $\%$ & 5,7 & 3,3 & $\overline{9,8}$ & 8,2 & 40,2 & 9,0 & 9,0 & 5,7 & 9,0 \\
\hline & $\mathrm{n}$ & 5 & 5 & 8 & 12 & 42 & 14 & & 10 & 17 \\
\hline & $\%$ & 4,1 & 4,1 & 6,6 & 9,8 & 34,4 & 11,5 & 7,4 & 8,2 & 13,9 \\
\hline 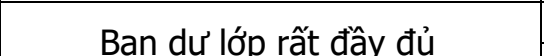 & $\mathrm{n}$ & 4 & $c$ & 3 & & 13 & & 3 & 8 & 90 \\
\hline Dận dụ & $\%$ & 3,3 & & 2,5 & & 10,7 & & & 6,6 & 73,8 \\
\hline & $\mathrm{n}$ & 3 & 3 & 3 & 11 & 44 & 17 & 13 & 9 & 19 \\
\hline & $\%$ & 2,5 & 2,5 & 2,5 & 9,0 & 36,1 & 13,9 & 10,7 & 7,4 & 15,6 \\
\hline Bạn hài lòng với c & $\mathrm{n}$ & 7 & 6 & 10 & 11 & 52 & 6 & 10 & 10 & 10 \\
\hline & $\%$ & 5,7 & 4,9 & 8,2 & 90, & 42,6 & 4,9 & 8,2 & 8,2 & 8,2 \\
\hline uết những việc bạn đan & $\mathrm{n}$ & 15 & 12 & 8 & 9 & 42 & 13 & 7 & 5 & 11 \\
\hline ng có & $\%$ & 12,3 & 9,8 & 6,6 & 7,4 & 34,4 & 10,7 & 5,7 & 4,1 & 9,0 \\
\hline Gần đây, bạn c & $\mathrm{n}$ & 45 & 7 & 9 & 6 & 29 & 11 & 4 & 3 & 8 \\
\hline
\end{tabular}




\begin{tabular}{|c|c|c|c|c|c|c|c|c|c|c|}
\hline $\begin{array}{l}\text { đến việc chuyển sang trường khác } \\
\text { để học }\end{array}$ & $\%$ & 36,9 & 5,7 & 7,4 & 4,9 & 23,8 & 9,0 & 3,3 & 2,5 & 6,6 \\
\hline \multirow{2}{*}{$\begin{array}{c}\text { Gần đây, bạn có suy nghĩ nhiêu } \\
\text { đến việc tạm dừng học và hoàn } \\
\text { thành chương trình sau }\end{array}$} & & & & & & & & & & 7 \\
\hline & $\%$ & 44,3 & 9,8 & 6,6 & 2,5 & 21, & 2, & 4,9 & 2,5 & 5,7 \\
\hline \multirow{2}{*}{$\begin{array}{l}\text { Bạn hài lòng với tất cả giảng viên } \\
\text { đã và đang học trong học kỳ }\end{array}$} & & 8 & 4 & 1 & & & f & 13 & 11 & 18 \\
\hline & $\%$ & 6,6 & 3,3 & & 10,1 & 28 & 4,9 & 10,1 & 9,0 & 14,8 \\
\hline \multirow{2}{*}{$\begin{array}{l}\text { Bạn hài lòng về tình hình học tập } \\
\text { của mình }\end{array}$} & & 3 & & & 14 & 25 & & 1 & 4 & 4 \\
\hline & $\%$ & 26,2 & 16,4 & 12,3 & 11 & 20,5 & 5,7 & 0 & 3,3 & 3,3 \\
\hline
\end{tabular}

Nghiên cứu cho thấy, kết quả của thang đo đạt giá trị phân loại ở mức trung bình. Sinh viên không gặp khó khẳn trong việc tham dự lớp đầy đủ và nhận thức được tầm quan trọng có được tấm bằng đại học. Tuy nhiên, một số tiêu chí sinh viên còn gặp nhiều khó khăn như việc theo kịp tiến độ học đại học, tỉ lệ hài lòng với kêt quả học tập và tình hình học tập của bản thân còn thấp.

3.3. Tương quan giữa kết quả học tập và mức độ thích ứng đối với học tập

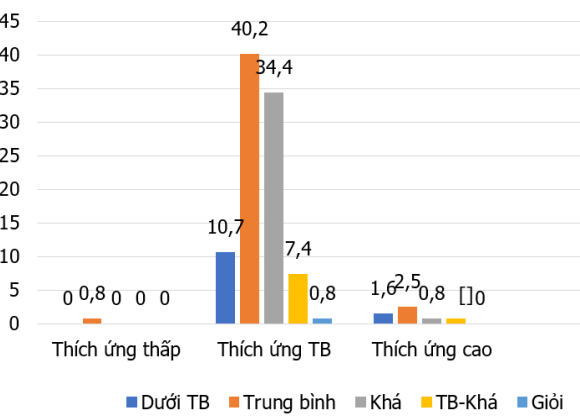

Biểu đồ 3.1. Kêt quả học tập và mức độ thích ứng của sinh viên
Trong nhóm thích ứng trung bình có 40,2\% sinh viên có kết quả học tập trung bình, 34,4\% sinh viên có kết quả khá, $0,8 \%$ sinh viên có kết quả giỏi.

3.4. Các yếu tố ảnh hưởng đến mức độ thích ứng với hoạt động học tập

3. 4.1. Các nhóm yếu tố ảnh hưởng đến mức độ thích ứng với hoat động học tập

Bảng 3.4. Các yếu tồ ảnh hưởng đến mức độ thích ứng với hoạt động học tập

\begin{tabular}{|c|c|c|}
\hline $\begin{array}{c}\text { Các nhóm yếu tố } \\
\text { ảnh hường }\end{array}$ & $\begin{array}{c}\text { Điểm } \\
\text { trung } \\
\text { bình }\end{array}$ & $\begin{array}{c}\text { Độ lệ̂ch } \\
\text { chuẩn }\end{array}$ \\
\hline $\begin{array}{c}\text { Nhà trường, cán bộ } \\
\text { khoa, phòng }\end{array}$ & 2,84 & 0,69 \\
\hline Giảng viên & 2,55 & 0,68 \\
\hline Bản thân sinh viên & 3,44 & 0,73 \\
\hline Gia đình sinh viên & 2,5 & 0,86 \\
\hline
\end{tabular}

Bản thân sinh viên là yếu tố ảnh hưởng lớn nhất đến mức độ thích ứng với hoạt động học tập (điểm trung bình là 3,44).

\subsubsection{Nhóm yếu tố liên quan tới nhà trường, cán bộ khoa, phòng}

Bảng 3.5. Nhóm yếu tố liên quan đến nhà trường, cán bộ khoa, phòng

\begin{tabular}{|c|c|c|}
\hline Tiêu chí & Điểm trung bình & Độ lệch chuẩn \\
\hline $\begin{array}{c}\text { Nhà trường chưa trang bị cho sinh viên kiến thức về kỹ } \\
\text { năng thích ứng với môi trường học tập. }\end{array}$ & 2,85 & 1,08 \\
\hline $\begin{array}{c}\text { Các câu lạc bộ, nhóm chưa thực phát huy tốt tác dụng } \\
\text { hồ trợ sinh viên năm thứ nhất. }\end{array}$ & 2,86 & 1,14 \\
\hline $\begin{array}{c}\text { Nhà trường chưa tổ chức các buổi tọa đàm về phương } \\
\text { pháp học tập, rèn luyện. }\end{array}$ & 2,67 & 1,13 \\
\hline $\begin{array}{l}\text { Việc phố biến các nội quy, quy chế chưa cụ thể, rõ ràng } \\
\text { đối với sinh viên năm thứ }\end{array}$ & 2,47 & 1,3 \\
\hline $\begin{array}{l}\text { Trang bị các kỹ năng sống cho sinh viên (giao tiếp, hoạt } \\
\text { động nhóm...) còn hạn chế. }\end{array}$ & 3,64 & 1,08 \\
\hline $\begin{array}{l}\text { Nhà trường chưa tạo được sự tin tưởng, gần gũi, thân } \\
\text { mật đối với sinh viên ngay từ những ngày đâu nhập học. }\end{array}$ & 2,75 & 1,12 \\
\hline $\begin{array}{c}\text { Cán bộ quản lý không phố biến đây đủ, rõ ràng mọi } \\
\text { thông tin liên quan đến môi trường học tập }\end{array}$ & 2,59 & 1,07 \\
\hline $\begin{array}{l}\text { Việc quản lý tân sinh viên được tiến hành một cách cứng } \\
\text { nhắc, thiếu đồng cảm. }\end{array}$ & 2,85 & 1,16 \\
\hline
\end{tabular}

Trong các yếu tố thuộc về nhà trường, cán bộ khoa phòng thì yếu tố trang bị các kỹ năng sống 
của sinh viên (giao tiếp, hoạt động nhóm...) còn hạn chế có điểm trung bình là cao nhất là 3,64.

3.4.3. Nhóm yếu tố liển quan tới giảng viên, cố vấn học tập

Bảng 3.6. Nhóm yếu tố liên quan tới giảng viên, cố vấn học tập

\begin{tabular}{|c|c|c|}
\hline Các tiêu chí & Điểm trung bình & Độ lệch chuấn \\
\hline $\begin{array}{l}\text { Giảng viên, cố vấn học tập chưa quan tâm đến việc } \\
\text { rèn luyện kỹ năng thích }\end{array}$ & 2,28 & 1,1 \\
\hline $\begin{array}{c}\text { Giảng viên còn thờ } \sigma \text {, thiếu nhiệt tình khi giúp đỡ sinh } \\
\text { viên khi gặp khó khăn. }\end{array}$ & 2,45 & 1,03 \\
\hline $\begin{array}{c}\text { Giảng viên và sinh viên ít có cơ hội trao đổi, tiếp xúc } \\
\text { trong và ngoài giờ học. }\end{array}$ & 3,16 & 1,0 \\
\hline $\begin{array}{c}\text { Trước khi dạy, giảng viên chưa giới thiệu chương } \\
\text { trình, hướng dẫn cách học }\end{array}$ & 2,05 & 1,05 \\
\hline $\begin{array}{l}\text { Giảng viên chỉ quan tâm đến nội dung bài giảng mà } \\
\text { chưa quan tâm đến việc hình thành kỹ năng học tập } \\
\text { cho sinh viên. }\end{array}$ & 2,79 & 1,07 \\
\hline
\end{tabular}

Trong các yếu tố liên quan tới giảng viên, cố vấn học tập thì yếu tố giảng viên và sinh viên ít có cơ hội trao đổi, tiếp xúc trong và ngoài giờ học có điểm trung bình cao nhất là 3,16.

\subsubsection{Nhóm yếu tố liên quan tới bản thân sinh viên}

Bảng 3.7. Nhóm yếu tố liên quan tới bản thân sinh viên

\begin{tabular}{|c|c|c|}
\hline Các tiêu chí & Điểm trung bình & Độ lệch chuẩn \\
\hline $\begin{array}{c}\text { Sinh viên chưa nhâan thức rõ vài trò của kỹ năng thích ứng } \\
\text { với môi trường học tập. }\end{array}$ & 3,31 & 1,0 \\
\hline $\begin{array}{c}\text { Sinh viên chưa được rèn luyện kỹ năng thích ứng với môi } \\
\text { trường học tập. }\end{array}$ & 3,35 & 1,01 \\
\hline $\begin{array}{c}\text { Sinh viên chưa tích cực tham gia hoạt động chung của } \\
\text { trường }\end{array}$ & 3,06 & 1,18 \\
\hline $\begin{array}{c}\text { Cách học và rèn luyện của sinh viên còn mang tính chất } \\
\text { đối phó, thụ động }\end{array}$ & 3,64 & 1,08 \\
\hline $\begin{array}{c}\text { Sinh viên chưa xác định được mục tiêu, kế hoạch thực } \\
\text { hiện hoặc xác định được nhưng không phù hợp với khả } \\
\text { năng bản thân và điều kiện khách quan. }\end{array}$ & 3,49 & 1,08 \\
\hline $\begin{array}{l}\text { Sinh viên còn thiếu tự tin, không chủ động giao tiếp bạn } \\
\text { bè, thây cô }\end{array}$ & 3,69 & 1,04 \\
\hline Sinh viên chưa nắm vững kiến thức và phương pháp học & 3,54 & 1,02 \\
\hline Sinh viên thiếu sự quyết tâm, tính kiên trì & 3,6 & 1,01 \\
\hline $\begin{array}{c}\text { Sinh viên chưa thực sự yêu thích, hứng thú với ngành, } \\
\text { nghề mà mình đã lựa chọn }\end{array}$ & 3,25 & 1,06 \\
\hline
\end{tabular}

Những yếu tố thuộc bản thân sinh viên có điểm trung bình cao: sinh viên còn thiếu tự tin, không chủ động giao tiếp bạn bè, thầy cô $(3,69)$, cách học và rèn luyện của sinh viên còn mang tính chất đối phó, thụ động $(3,64)$, sinh viên thiếu quyết tâm và kiên trì $(3,6)$

\section{BÀN LUẬN}

4.1. Kết quả mức độ thích ứng đối với hoạt động học tập của sinh viên năm thứ nhất Khoa Xét nghiệm trường Đại học Kỹ thuật $Y$ tế Hải Dương. Nghiên cứu của chúng tôi cho thấy, sinh viên năm thứ nhất khoa Xét nghiệm trường Đại học Kỹ thuật Y tế Hải Dương đạt ở mức độ thích ứng trung bình $(93,4 \%)$ đối với hoạt động học tập. Kết quả này cũng phù hợp với nghiên cứu tác giả Võ Văn Việt $(87,4 \%)[3]$. Trong nhóm thích ứng trung bình có $40,2 \%$ sinh viên có kết quả học tập trung bình, 34,4\% sinh viên có kết quả khá, 0,8\% sinh viên có kết quả giỏi.

Trong các tiêu chí của bảng thích ứng với học tập, tỷ lệ sinh viên lựa chọn cao trong việc tham dự lớp đầy đủ và nhận thức được việc có được tẩm bằng đại. Tuy nhiên, một số tiểu chí sinh viên còn gặp nhiêu khó khăn như việc theo kịp tiến độ học đại học, tỉ lệ hài lòng với kêt quả học tập và tình hình học tập của bản thân còn thấp. Kết quả này cùng phù hợp với nghiên cứu của tác giả Võ Văn Việt [3]. Học tập trong môi trường đại học có sự khác biệt rất lớn đối với chương trình học phổ thông, đặc biệt với môi trường thuộc khối ngành sức khỏe như trường 
Đai học Kỹ thuât Y tế Hải Dương. Sự khác biêtt về chương trình đào tạo, nội dung kiến thức, phương pháp giảng dạy... đã tạo ra rất nhiều khó khăn trong việc thích ứng với sinh viên năm thứ nhất. Nhiều sinh viên khi học đai học cảm thấy bõ ngõ, lượng kiến thức quá tải, chưa tìm ra được phương pháp học tập phù hợp dẫn đến tâm lý chán nản khi theo học.

4.2. Xác định một số yếu ảnh hưởng đến mức độ thích ứng đối với học tập của sinh viên năm thứ nhất Khoa Xét nghiệm trường Đai hoc Kỹ thuât $Y$ tế Hải Dương

4.2.1. Các nhóm yểu tố ảnh hưởng đến mức độ thích ứng đối với học tập. Trong các nhóm yếu tố ảnh hưởng tới mức độ thích ứng của sinh viên năm thứ nhất đối với học tâp thì yếu tố bản thân sinh viên có điểm trung bình cao nhất $(3,44)$, các nhóm yếu tố còn lại có điểm trung bình dưới 3,0 . Điều này cho thấy yếu tố bản thân sinh viên có ảnh hưởng nhiều nhất tới khả năng thích ứng với học tâp. Kết quả này cũng phù hợp với nghiên cứu của tác giả Nguyễn Thị Thu An khi phân tích những nhân tố ảnh hưởng đến kết quả học tập của sinh viên. [4]

4.2.2. Nhóm yểu tố liên quan tới nhà trường, cán bộ khoa, phòng. Trong các yếu tố có liên quan tới nhà trường, các cán bộ khoa, phòng thì điểm trung bình cao nhất là yếu tố trang bị các kỹ năng sống của sinh viên (giao tiếp, hoạt động nhóm...) còn hạn chế $(3,64)$. Kết quả này tương đương với nghiên cứu của tác giả Trần Thị Minh Đức. [5]

4.2.3. Nhóm yếu tố liên quan tới giảng viên, cố vấn học tập. Trong các yếu tố có liên quan tới giảng viên điểm thì yếu tố giảng viên và sinh viên ít có cơ hội trao đổi, tiếp xúc trong và ngoài giờ học có điểm trung bình cao nhất là 3,16 . Kết quả này tương đương với nghiên cứu của tác giả Trần Thị Minh Đức $(37,6 \%)$ [5]. Trong các mối quan hệ ở trường đại học, mối quan hệ giữa giảng viên và sinh viên là mối quan hệ mà sinh viên năm thứ nhất cảm thấy khó khăn nhất. Điều này có thể được lý giải do sinh viên năm thứ nhất vẫn còn bõ ngõ̃, nhiêu sinh viên còn có tâm lý e ngại khi tiếp xúc với giảng viên, cố vấn học tập.

4.2.4. Nhóm yếu tố liên quan tới bản thân sinh viên. Trong các tiêu chí thuộc nhóm yếu tố có liên quan tới bản thân sinh viên điểm trung bình dao động từ 3,1 đến 3,7. Những yếu tố thuộc bản thân sinh viên có điểm trung bình cao: sinh viên còn thiếu tự tin, không chủ động giao tiếp bạn bè, thầy cô $(3,69)$, Cách học và rèn luyện của sinh viên còn mang tính chất đối phó, thụ động $(3,64)$, sinh viên thiếu quyết tâm và kiên trì $(3,6)$. Thực tế sinh viên năm thứ nhất vẫn còn rất nhiêu bõ ngõ khi bước chân vào học đại học; các kỹ năng sống như kỹ năng giao tiếp, kỹ năng tự học, kỹ năng lập kế hoạch... ngay từ trường phổ thông còn rất nhiều hạn chế.

4.2.5. Nhóm yếu tố liên quan tới gia đình sinh viên. Trong các tiêu chí thuộc nhóm yếu tố có liên quan tới gia đình sinh viên điểm trong nhóm yếu tố về gia đình thì yếu tố có điểm trung bình cao là "Gia đình định hướng ngành nghề cho con mà không quan tâm đến năng lực, sở thích của con". $(3,01)$. Đây cũng là thực trạng phổ biến trong việc chọn trường tại các gia đình ở Việt Nam hiện nay, dẫn đến sinh viên bước vào môi trường đại học cảm thây việc học không phù hợp với khả năng của mình, học mang tính chất đối phó.

\section{KẾT LUÂ̂N}

- Sinh viên năm thứ nhất khoa Xét nghiệm trường Đại học Kỹ thuật $Y$ tế Hải Dương đạt ở mức thích ứng trung bình $(93,4 \%)$ với hoạt động học tập.

- Sinh viên còn gặp nhiều khó khăn như việc theo kịp tiến độ học đại học, tỉ lệ hài lòng với kềt quả học tập và tình hình học tập của bản thân còn thấp.

- Trong nhóm thích ứng trung bình có 40,2\% sinh viên có kết quả học tập trung bình, 34,4\% sinh viên có kết quả khá, $0,8 \%$ sinh viên có kết quả giỏi.

- Trong các nhóm yếu tố ảnh hưởng tới mức độ thích ứng đối với học tập của sinh viên năm thứ nhất thì yếu tố bản thân sinh viên được đánh giá là ảnh hưởng nhiều nhất.

\section{TÀI LIÊU THAM KHẢO}

1. Cao Thi Thanh Nhàn (2016), "Thích ứng tâm lý - xã hối của sinh viên năm thứ nhất trướng Đạ học Hải Phòng", Đại học quốc gia Hà Nội, Trường Đại hoc Khoa học xã hổi và nhân văn.

2. Nguyễn Đức Quỳnh (2014), "Thích ứng với hoạt động học tập của sinh viên năm thứ nhất trường Đai hoc phờng cháy chữa cháy", Đai hoc quốc gia Hà Nội, Trường Đại học Khoa học xã hội và nhân văn.

3. Võ Vằn Viêt (2018), "Đo lường sử thích ứng của sinh viên năm thứ nhất với môi trường đại học", Tạp chí Khoa học ĐHQGHN: Nghiên cứu Giáo dục tâp 34 , số 3 .

4. Nguyến Thị Thu An (2016), "Những nhân tố ảnh hưởng đến kết quả học tập của sinh viên năm I-II trường Đại học Kỹ thuật - công nghệ Cần Thơ", Tap chí Khioa học Trường Đai học Cần Thớ.

5. Trần Thị Minh Đức (2004), "Nghiên cứu sự thích ứng của sinh viên năm thư nhất trường Đại học Quốc gia Hà Nôi với môi trường Đại học", Đại học Quốc gia Hà Nội. 